\title{
Comunicação e reflexividade
}

(1) HABERMAS, Jürgen; Mudança Estrutural da Esfera Pública; RU, Tempo Brasileiro, 1984, p. 29. (2) Segundo Habermas, "a história é então experenciada como um processo abrangente de geração de problemas - e o tempo, como recurso escasso para o domínio desses problemas que são empurrados para o futuro". Em HABERMAS, Jürgen; A Constelação Pós-Nacional - Ensaios Políticos; SP, Littera Mundi, 2001, p. 169.

Lavina Madeira Ribeiro é doutora em Ciências Sociais pela Unicamp-SP. Leciona no Programa de PósGraduação da Faculdade de Comunicação da Universidade de Brasília e publicou, entre outros, o I Contribuições ao Estudo Institucional da Comunicação, EDUFPI, Teresina, 1996.

\section{Resumo}

Este ensaio aborda o conceito de reflexividade aplicado ao estudo empírico dos conteúdos veiculados em revistas semanais de maior alcance nacional, no sentido de identificar os mecanismos que o dinamizam.

\section{Comunicação reflexiva}

De que modo as instituições de comunicação delimitam sua especificidade discursiva? A análise da ação discursiva destas instituições, tais como emissoras de televisão, rádios, jornais e revistas expõe mecanismos e procedimentos que revelam sua dinâmica argumentativa no espaço público comunicativo. Há um consenso no pensamento sociológico contemporâneo sobre a importância das instituições de comunicação para a experiência e a formação de opiniões e comportamentos dos indivíduos nas sociedades atuais. Reflexões sobre processos de globalização, de rupturas da nacionalidade, de configuração de estilos de vida e de transformações nas configurações de posição e ação dos sujeitos sociais reconhecem sempre a presença interventora das instituições de comunicação.

Estas instituições têm adquirido um crescente poder de influência sobre o curso da vida social e cabe particularmente a este ensaio pensar sobre a natureza desta influência. Parte-se do pressuposto de que o terreno de atividades e simbolizações das práticas veomunicativas não se confunde com aqueles de outros territórios de produção de sentido e valor. Há uma especificidade institucional destas práticas, um lugar próprio de agenciamento discursivo que não é o mesmo daqueles relativos à esfera da ciência, da política e da arte e cultura em geral.

Além disso, por mais diferentes que sejam as estruturas comunicativas, seu poder de alcance e públicos, elas mantém entre si relações de complementariedade, conflito, concorrência e interdependência. Isto porque há princípios e critérios institucionais que antecedem sua diversidade estrutural. Pensar sobre estes princípios e critérios nos remete à origem histórico-sociológica destas instituições. Para Jürgen Habermas, a informação se desenvolveu paralelamente à expansão da troca de mercadorias ${ }^{1}$. Esta é uma interpretação econômica da origem institucional da comunicação que não esclarece a especificidade dos contornos discursivos historicamente assumidos primeiro pelas folhas impressas e, posteriormente, pelas demais estruturas de comunicação.

Em outra reflexão mais filosófica sobre a origem da modernidade, Habermas a associa à emergência de uma "consciência temporal" que opõe o moderno ao antigo e inaugura uma concepção histórica processual da vida, cujo horizonte é um futuro que não pode ser previsto $^{2}$. Diante de um presente contingente e de um futuro incerto, o que conceitua essencialmente a modernidade é a razão. Ela é o suporte para o exercício da crítica e para a fundação de uma humanidade que busca a autocompreensão criando suas próprias regras. Este movimento gerou a diferenciação das esferas do saber ciência, moral e arte - e é dentro dele 
que se pode encontrar os fundamentos para a institucionalização das estruturas de comunicação.

O exercício da crítica, o julgamento subjetivo dos fatos e das opiniões, a autoatualização demandadas pelo movimento da processualidade histórica são os procedimentos exigidos do público que forma o espaço público comunicativo. Se o princípio da subjetividade está no âmago da modernidade, também se faz presente na institucionalização da comunicação como mecanismo que compele os indivíduos a buscarem em si os recursos críticos para sua autonomia e autodeterminação.

As instituições de comunicação pressupõem este procedimento de intervenção crítica sobre o mundo, a partir do cultivo de uma subjetividade que se quer autônoma diante de "um mundo da vida que perde de modo perturbador os seus traços de confiança, de transparência e de fidelidade"3. $\mathrm{O}$ discurso comunicativo evoca a crítica e o julgamento subjetivo sobre um pano de fundo de elementos que se sucedem em transformações ininterruptas $\mathrm{e}$ imprevisíveis. As instituições de comunicação são, portanto, formações próprias da modernidade, ancoradas no uso público da razão.

A comunicação tem grande visibilidade no mundo contemporâneo participando expansivamente dos processos reflexivos da sociedade de risco. Segundo Ulrich Beck a sociedade de risco surgiu a partir dos efeitos colaterais e das ameaças cumulativamente produzidos pela sociedade industrial. Ela forja uma "modernização reflexiva" em toda a sociedade - onde ela se defronta com ameaças não absorvidas pelo industrialismo e o modelo clássico de sociedade industrial, cujos ícones de progresso são o capital, a tecnologia e o mercado ${ }^{4}$. As instituições de comunicação basicamente expõem a dinâmica deste autoconfronto. Expõem exatamente aqueles momentos de ruptura onde os riscos reais e potenciais ameaçam os limites sociais de segurança dos indivíduos e das instituições.
Segundo Ulrich Beck, "a definição do perigo é sempre uma construção cognitiva e social" ${ }^{5}$. Estas definições são extensiva e ostensivamente construídas pelas instituições de comunicação e, neste sentido, elas participam desta modernização reflexiva e se constituem em si em instituições que produzem a sua própria reflexividade. Estão na pauta diária dos discursos jornalísticos, dos documentários e outros gêneros informativos questões relativas a todas as ordens sociais e naturais. Questões emergentes sempre em função de problemas gerados pelo curso do processo industrial das sociedades contemporâneas, cujas rupturas e ameaças dizem respeito a um largo espectro de variáveis, tais como recursos naturais, recursos produtivos, como a divisão social do trabalho, recursos culturais, concepções políticas, jurídicas, científicas, costumes e concepções de vida.

Como os riscos emergem simultaneamente com as decisões e opiniões formuladas no meio social, as instituições de comunicação estão sempre se autoconfrontando com estes riscos. Interessa, em particular, como elas exploram os seus termos, que mecanismos de sua reflexividade entram em ação, ou seja, de que recursos dispõem para enfrentar as ameaças que emergem cotidianamente na vida social. Ameaças evidentes e ameaças construídas pela discursividade pública.

Conforme Ulrich Beck, a sociedade toma-se reflexiva quando "ela se toma um tema e um problema para si própria"6. Há, segundo ele, dois ambientes especializados onde estas tematizações e problematizações alcançam relevo: no contexto das práticas científicas laboratoriais, cujos resultados têm pouco controle sobre as conseqüências e repercussões sociais e no contexto de uma "discursividade pública da experiência"”, profundamente presa à experiência e dependente da ação das instituições de comunicação.

Este segundo contexto, conforme o autor, está mais propenso a suscitar dúvidas e perguntas do que a fornecer respostas e depende, na sua argumen-
(3) Idem, p. 172

(4) BECK, Ulrich, GIDDENS, Anthony e LASH, Scott; Modemização Reflexiva - Política, Tradição e Estética na Ordem Social Moderna; SP, Ed. Unesp, 1997, p. 16. Segundo Beck, "'modernização reflexiva' significa autoconfrontação com os efeitos da sociedade de risco que não podem ser tratados e assimilados no sistema industrial", p. 16.

(5) Idem, p. 17. (6) Idem, p. 19. (7) Idem, p. 44. 
(8) LASH, Scott; "A Reflexividade e seus Duplos: Estrutura, Estética, Comunidade"; em BECK, $U_{\text {, }}$ GIDDENS, A . LASH, S. Modemização Reflexiva. Op. cit, p. 182.

(9) BECK, U. Op. cit, p. 61.

(10) BECK, $U$. The Reinvention of Politics - Rethinking Modemity in the Global Social Order. Cambridge, Polity Press, 1997. Afirma o autor, "the culture of doubt, cultivating doubt and helping it into forms of public representation and recognition, does not prohibit anything, force anything or proselytise anyone with anything; instead it makes the most varied and conflicting things possible, but in moderated form, subverted and brightned up by doubt. Doubting, something that appeared as weakness and decay to cultures of faith and certainty, now becomes a virtue, the lauching point for productivity", p. 171.

(11) HABERMAS, Jürgen. "Acerca da Autocompreensão da Modernidade". Em HABERMAS, J. A Constelação Pós-Nacional. Op. cit. Segundo ele, "a modernidade deve ser continuada com vontade política e com consciência. E para essa forma de auto-influxo democrático é decisiva a instituição de procedimentos de formação discursiva da opinião e da vontade. Não apenas a formação política da vontade dos cidadãos, mas também a vida privada dos cidadãos da sociedade não pode prescindir de fonte de solidariedade gerada discursivamente. À medida que as condições padronizadas de vida e os planos de carreira se dissolvem, os indivíduos sentem diante das opções multiplicadas o crescente fardo das decisões (ou arranjos) que eles mesmos têm que tomar (ou negociar). A pressão para a 'individualização' exige a descoberta e a construção simultâneas de novas regras sociais. Os sujeitos livres - que não estão mais conectados a papéis tradicionais e não são dirigidos por eles - devem criar ligações graças aos seus próprios esforços de comunicação". pp. 197-198. tação pública, de referentes fornecidos pela ciência universitária. A ponte com a esfera da experiência da vida cotidiana demarca um outro princípio específico $\mathrm{da}$ discursividade institucional da comunicação pública. As dúvidas e perguntas fomentadas por esta discursividade advém desta forte ligação com a experiência, com o cotidiano, onde a materialização de riscos e ameaças se desdobra em inúmeras questões fornecendo um campo quase irrestrito de temáticas e possibilidades de problematização pública. A esfera política onde as instituições de comunicação tecem a relação entre riscos e opiniões está fincada na experiência da vida cotidiana, onde são tomadas decisões, feitas escolhas, num plano essencialmente privado da existência.

As instituições de comunicação invadem desde este plano mais íntimo e particular da vida individual àquele das grandes organizações públicas e privadas. Seu espectro de atuação é amplo e cada vez mais presente, devido à sua crescente sofisticação tecnológica. Formam, segundo Scott $\mathrm{Lash}^{8}$, novas comunidades de informação e comunicação baseadas em sistemas especialistas, cuja racionalidade opera sobre as significações compartilhadas no sentido de reparar suas rupturas. Os discursos dos especialistas vêm reparar estas quebras na rotina de segurança da vida cotidiana como discursos legitimadores desta rotina. Como agentes singulares, entretanto, cabe observar que as instituições de comunicação nem sempre atuam como agentes reparadores de rupturas. Muitas vezes, intervém antecipadamente criando realidades e fatos.

Com relação aos mecanismos que põem em prática a reflexividade pública da comunicação, cabe refletir a respeito do fato que eles são incorporações de sistemas especialistas. Para Ulrich Beck, a modernização reflexiva requer uma "reforma da racionalidade", já que a racionalidade da ciência, seus padrões e métodos explicativos tornaram-se incapazes de conter o fluxo incessante de novas ameaças e riscos enfrentados nas sociedades contemporâneas. A racionalidade científica deve ser, de algum modo, substituída por uma política reflexiva, baseada na evidência de que "o microcosmo da conduta da vida pessoal está inter-relacionado com o macrocosmo dos problemas globais"9. Baseada no exercício da dúvida, que permeia e envolve as esferas existenciais e institucionais, a ação política consiste na assunção da dúvida como variável que não pode mais ser controlada pelos métodos científicos, posto que a própria ciência natural e social convive com a dúvida como parte do conhecimento. A dúvida, segundo o autor, possibilita a multiplicidade de vozes de todos os lados e de cada um de nós ${ }^{10}$. Torna possível a emergência da diversidade e do conflito. Esta política põe em questão as soluções científicas em favor da dúvida e exerce, assim, uma crítica sobre os sistemas especialistas como fontes legitimadoras da reflexividade pública.

Sociedades reflexivas têm que encontrar soluções por si para os problemas criados sistemicamente pela modernização social. Para Habermas, a reflexividade gerada pelos atores coletivos deve ser realmente política. Os atores só podem conter os custos dos riscos sistêmicos a partir da formação discursiva da opinião e da vontade, de um procedimento democrático de racionalização do mundo da vida que constantemente restabelece consensos desfeitos e defasados com novos arranjos normativos. A racionalidade comunicativa é, assim, segundo Habermas, uma força produtiva "importante para os desafios da 'modernização reflexiva" "pl 11 .

A racionalidade comunicativa como procedimento de uma reflexividade política que busca respostas aos impasses da modernização deve ser compreendida como uma proposta de ação na ésfera da discursividade pública. A questão que se coloca é se esta racionalidade, do ponto de vista das instituições de comunicação, é essencialmente política ou, em outras palavras, se ela prescinde da ciência, do discurso especialista e, para além disso, 
se na busca de alternativas para os autoconfrontos enfrentados com os riscos e ameaças da sociedade industrial, realiza uma crítica à ciência. $\mathrm{O}$ que está em questão basicamente são os mecanismos legitimadores da reflexividade pública, seja na esfera mais ampla do debate público, seja no interior das estruturas de comunicação.

Enquanto Habermas e Beck fixam uma proposta de ação reflexiva essencialmente política, uma politização generalizada das esferas da discursividade pública, Anthony Giddens, o fundador do conceito de reflexividade, o descreve como procedimento baseado na confiança em sistemas especialistas. Para Giddens, o conhecimento científico tem substituído a tradição no movimento de busca dos indivíduos por fontes de segurança ontológica. A insegurança gerada pelas transformações sociais e suas rupturas de estruturas tradicionais é enfrentada pela absorção de sistemas abstratos de conhecimentos - teorias, conceitos e descobertas - que, apesar de voláteis, mantém níveis aceitáveis de segurança e ordem. Segundo Giddens, "em todas as sociedades, a manutenção da identidade pessoal, e sua conexão com identidades sociais mais amplas, é um requisito primordial de segurança ontológica"12. As sociedades atuais, enquanto sociedades pós-tradicionais, enfrentam as incertezas da vida incorporando o conhecimento especializado desde o âmbito mais íntimo da vida privada àquele das instituições sociais. Esta apropriação se impregna na experiência da vida cotidiana, nos estilos de vida e na esfera do trabalho. Por mais que a ciência não possa ser inconteste em sua autoridade explicativa, ela se desdobra em sistemas especialistas, segundo Giddens, abertos e alternativos, que são incorporados e desincorporados na relação dialética com os estilos de vida ${ }^{13}$.

Esta concepção da reflexividade ancorada em sistemas especialistas difere dos autores anteriores porque não é uma proposta de ação, mas uma afirmação categórica com ambição explicativa sobre os mecanismos operativos e dinamizadores da vida social. Assusta, de certo modo, crer que esta dinâmica tenha, como recurso central, sistemas científicos cujos critérios evolutivos nem sempre respeitam limites éticos e humanistas. Se, para Giddens, a ciência, os sistemas abstratos, a tecnologia têm papel central na experiência, no modo sobretudo como indivíduos leigos se atualizam sobre questões de relevância pessoal e pública, ao que tudo indica, ele se baseia em evidências advindas, seja do modo como o mundo sistêmico, econômico e tecnológico absorve suas crises, como diz Habermas, auto-aplicando retroativamente procedimentos resultantes de suas próprias leis internas, sem prestar contas às repercussões de seus sistemas funcionalmente diferenciados para setores mais amplos da sociedade, seja em razão do recurso ao conhecimento científico como fonte legitimadora da discursividade pública política e comunicativa, por mais provisórios, parciais e superficiais que sejam os termos deste recurso ${ }^{14}$. $\mathrm{Na}$ visão de Giddens, por mais que a ciência e a tecnologia se infiltrem em todas as esferas da vida social, elas não são aceitas sem ressalvas. Os indivíduos já incorporaram a idéia do "caráter essencialmente fluido da ciência", do fato de que ela está constantemente reformulando suas explicações e receitas. Mas, a administração dos riscos, por mais cautelares que sejam os indivíduos e instituições com relação às voláteis prescrições científicas, todos ainda continuam, em última instância, presas de suas alternativas.

Há, entretanto, um conjunto de movimentos identitários que fogem à alçada da ciência e da tecnologia. São movimentos de minorias, conflitos de gênero, raciais e outros cujos avanços não foram baseados em critérios de legitimação científicos, mas essencialmente éticos e políticos. Mesmo valendo-se da oposição tradiçãomodernidade com a qual Giddens analisa a questão, por exemplo, da família e seus novos desafios na atualidade, ele próprio não recorre a fontes científicas para apontar os
(12) GIDDENS, Anthony. "A Vida em uma Sociedade Pós- Tradicional", em BECK, U., GIDDENS, A. LASH, S; Modernização Reflexiva. Op. cit, p. 100.

(13) Idem, p. 112. Segundo Giddens, "o mais importante de tudo é que a confiança nos sistemas abstratos está ligada a padrões de estilo de vida coletivos, eles próprios sujeitos a mudança. (...) Nas sociedades modernas as escolhas de estilo de vida são ao mesmo tempo constitutivas da vida cotidiana e ligadas a sistemas abstratos (...) As alterações nas práticas de estilo de vida podem se tornar profundamente subversivas dos sistemas abstratos centrais".

(14) Em ensaio sobre a noção de "risco", Giddens refere-se, em várias passagens, à atitude dos governos justificando suas políticas com base em dados cient́ficos e às escolhas dos indivíduos também baseadas em informações desta natureza. Ver GIDDENS, Anthony. Mundo em Descontrole - O Que a Globalização Está Fazendo de Nós. $R J$, Record, 2000, pp 40-41. 
(15) GIDDENS, Anthony. Mundo em Descontrole - O Que a Globalização Está Fazendo de Nós. RJ, Record, 2000, p. 71.

(16) Há um longo trabalho no âmbito da sociologia da cultura que explora a dinâmica dos estilos de vida baseada na noção de distinção social de Pierre Bourdieu. Neste aspecto, ver FEATHERSTONE, Mike. Cultura de Consumo e PósModernismo. SP, Studio Nobel, 1995.

(17) A pesquisa foi realizada com base numa amostra recolhida durante seis meses, no período de abril a setembro de 2001, com as edicõos semanais, num total de 48 exemplares. Escolheram-se duas revistas de maior circulação nacional, com um conteúdo jornalístico que pretende ser um resumo dos fatos mais significativos da semana. Ambas as revistas têm editorias de política nacional e intemacional, economia, aultura e sociedade. Considera-se que assim, elas pretendem fazer uma cobertura geral dos fatos mais importantes da realidade brasileira. indicadores das transformações neste ambiente. Os critérios aqui são baseados no debate sobre igualdade de direitos, sobre o eco de valores democráticos nos relacionamentos familiares ${ }^{15}$.

Giddens vê um movimento dialético entre sistemas abstratos e estilos de vida, onde alterações nestes últimos têm repercussões sobre os primeiros. Até que ponto, entretanto, os estilos de vida estariam preponderantemente comprometidos com os referenciais destes sistemas? O conhecimento especialista já teria impregnado todas as esferas daqueles conjuntos articulados de práticas, valores, comportamentos, gostos, saberes, escolhas e experiências próprias dos estilos de vida de um grupo ou de uma classe? Esta questão é importante porque pode subsumir a própria política aos sistemas especialistas e envolver as instituições de comunicação como instâncias vitais na legitimação destes sistemas. Além disso, os estilos de vida refletiriam distinções sociais ${ }^{16}$ cultivadas pelos próprios sistemas especialistas, entre os quais, as instituições de comunicação.

Para dar maior concretude às questões até aqui apresentadas, tomase como elemento de reflexão, o conteúdo informativo de duas revistas semanais brasileiras, Veja e Isto $E^{17}$, de maior circulação no país, cujas políticas editoriais são orientadas no sentido de abranger os fatos mais relevantes da realidade do país. A análise empírica destas publicações apresenta um conjunto de dados novos para o debate em curso.

Autocompreensão, racionalização da experiência, tematização de riscos e focos de insegurança ontológica da vida em sociedades complexas, estes são os procedimentos destas publicações. O presente contingente e o futuro incerto são enquadrados numa teia explicativa cuja finalidade é a de reduzir e controlar elementos que possam vir a ameaçar o senso de domínio sobre a rotina da vida cotidiana. Estas publicações realizam um exercício público de atualização dos indivíduos sobre temáticas que demandam perma- nentemente novas racionalizações porque nunca são esgotados os esclarecimentos sobre suas manifestações, desafios e riscos.

Os temas sobre os quais há uma reflexividade inclinada a controlar e pacificar problemas têm origem, na maior parte, nos focos de insegurança da vida privada. Assim, encontram-se reportagens longas de capa sobre os mais diversos assuntos, tais como a impotência sexual masculina, a saúde dentária, comportamento dos jovens de classe média, violência urbana, luta contra o câncer, automedicação, formas de lazer, depressão infantil, divórcio, autonomia no trabalho, avanços da inteligência humana, cuidados com a saúde física, solidão, aposentadoria, clonagem humana, padrões de masculinidade, sucesso empresarial, relações pessoais no ambiente de trabalho, capacidade de domínio do idioma, além de encartes em edições especiais sobre saúde familiar, novos usos domésticos da tecnologia e segurança caseira. Todos estes temas têm em comum o fato de serem problemas tipicamente próprios da classe média brasileira, o que lhes confere um contorno específico, limitado à experiência da vida privada de um segmento muito estreito da população do país. Aquela faixa restrita de leitores que mantém a sociedade de consumo. Um público que vivência desafios próprios de sociedades complexas, de quem tem acesso e está exposto aos seus riscos e ameaças e busca reflexivamente soluções para eles.

É significativo o fato destes temas terem recebido destaque dentre todos os demais assuntos da semana. Eles não são exclusivamente nacionais, pelo contrário, são problemas globais, comuns às classes médias de outros países, porque decorrentes de um modelo de sociedade industrial amplamente desenvolvido no mundo ocidental. $\mathrm{O}$ destaque de primeira página revela a intenção explícita das revistas de atualização do debate público sobre eles, sintonizando os leitores com esferas de reflexividade transnacionais.

Estes temas são como feridas 
abertas para os quais a discursividade comunicativa recursivamente se volta, com mecanismos próprios de abordagem e busca de soluções. Todos estes temas têm forte ligação com a experiência da vida cotidiana e, neste sentido, o discurso é dirigido diretamente aos indivíduos comuns, aos leitores singulares. As instituições de comunicação invadem estes planos íntimos da experiência tornando-os objetos de relevância pública. Se o discurso comunicativo é reparador das rupturas da rotina de segurança da vida cotidiana, também é criador destas rupturas, pelo próprio relevo que lhes confere, ao explorar estes temas em reportagens com grande destaque e detalhamento. Os recursos discursivos postos em prática para o autoconfronto com estes temas trazem à tona a questão acerca da presença do discurso especialista como fonte esclarecedora que vai garantir sensações de segurança aos indivíduos. A análise revela que este recurso é amplamente utilizado e se constitui, em geral, na principal fonte de esclarecimento e proposição de soluções. Há, entretanto, uma série de outros recursos que vêm associados ao discurso científico como suportes explicativos e que legitimam outras áreas da experiência e produção de sentido. Ë certo que estes mecanismos utilizados pelas revistas têm uma atuação coesa no sentido de funcionar como agentes redutores da ansiedade dos indivíduos, da insegurança e do isolamento provocados pelo intrínseco caráter de risco das sociedades atuais. Neste sentido, formam, como afirma Scott Lash, "comunidades de informação e comunicação", ou seja, comunidades aconchegadas sob o manto de uma reflexividade pacificadora feita de indivíduos leigos que interagem com estas publicações. Cria-se, assim, uma rotina de processos de aprendizagem feita pelo contínuo acesso aos conteúdos destas publicações, onde são incorporados seus mecanismos legitimadores de práticas e instituições sociais.

Os assuntos explorados podem ser divididos em áreas distintas, tais co- mo temas sobre o corpo, que envolvem, por exemplo, questões de saúde, sexualidade, reprodução; temas sobre a vida familiar, que falam sobre relacionamentos e segurança; temas sobre a vida urbana, que tratam da violência, solidão, do lazer e temas sobre a vida profissional. As questões sobre o cor-

po, ligadas ao seu desenvolvimento e saúde, têm uma abordagem que segue, em geral, a mesma cadeia exploratória. Há sempre uma introdução da polêmica em pauta, seja ela sobre a clonagem de seres humanos, ou sobre a automedicação, o desenvolvimento da inteligência humana ou a boa forma física. Colocadas as variadas questões que compõem a polêmica, em geral abertas e sem soluções unívocas, temse um desdobramento do tema onde tervém sistemas explicativos de ordens diversas, mas onde o conhecimento entífico e tecnológico tem lugar central. No caso do debate sobre a clonagem humana ${ }^{18}$, por exemplo, os termos descritivos do tema são todos advindos do conhecimento médico. Os depoimentos são feitos por cientistas, médicos, pesquisadores de clínicas especializadas. Além dos conteúdos científicos, que abrangem $95 \%$ da reportagem, falam o Estado, a igreja, organismos internacionais e fundações pró-clonagem.

Do ponto de vista da formação de opinião sobre o assunto, a fonte quase exclusiva de fornecimento de informações é o conhecimento científico. O leitor julga se apoia ou não a clonagem humana confrontando dados científicos apresentados, avaliando os riscos e violações éticas envolvidos. Neste aspecto, a ciência é a fonte substitutiva de referentes herdados da tradição cultural. O fato de não ser totalmente capaz de assegurar a clonagem humana sem falhas não a deslegitima como maior autoridade na discussão do tema pelas revistas.

Há, em todas as reportagens sobre o corpo a mesma rotina discursiva apoiada centralmente no conhecimento científico, nos recursos da medicina e de seu aparato tecnológico e farmacêutico. $\mathrm{O}$ procedimento explicativo que
(18) "Começou a Corrida para Fazer o Primeiro Clone Humano", Veja, ed. 1713, ano 34, $n^{\circ} 32$, de 15.08.2001 
(19) "Saúde e Vitalidade dos 8 aos 80", Veja, ed. 1708, ano 34, n²7, de 11.07.2001.

"A Nova Pílula do Amor", Isto É, no 1656, de 27.06.2001.

"Sem Receita: Os Perigos da Automedicação", Isto É, n' 1671, de 10.10.2001.

"O Poder da Mente", Veja, ed.

1706, ano 34, $n^{\circ} 25$, de

27.06.2001.

Todas as matérias acima são reportagens de capa das revistas (20) "Sua Segurança", encarte Veja Especial, da edição ano $34, n^{\circ} 23$, de 13.06.2001

(21) Para a elaboração desta longa reportagem sobre segurança, conforme descrito no editorial de abertura, uma equipe de repórteres realizou "mais de 220 entrevistas com especialistase consultou dezenas de pesquisas a respeito do assunto", considerando ser este trabalho jornalístico"o primeiro grande guia de segurança publicado no Brasil'. Encarte Veja Especial, da edição ano $34, n^{\circ} 23$, de 13.06.2001

(22) Ao todo, a revista ouviu a Sociedade Brasileira de Pediatria, a Faculdade de Saúde Pública da USP-SP, o Centro Brasileiro de Informações sobre Drogas Psicotrópicas, a Sociedade Brasileira de Ortopedia e Traumatologia, o Hospital SírioLibanês de SP, o Instituto LatinoAmericano das Nações Unidas para a Prevenção do Delito do Tratamento do Delinqüente (Ilanud), a empresa inglesa especializada em segurança de exeartivos Control Risk Groups, a empresa americana especializada em gerenciamento de riscos Kroll Associates, o Centro Brasileiro de Estudos e Pesquisas Judiciais, a psicóloga Marilda Lipp, com pósdoutorado em stress social no National Institute of Health, USA, o desenvolve estas temáticas sustenta-se predominantemente nos recursos do discurso especialista e, a partir dele, fornece receituários sobre como lidar com os problemas em pauta, como tomar decisões e fazer escolhas. $\mathrm{Na}$ reportagem sobre boa forma física, todos os caminhos discursivos desembocam em aconselhamentos baseados em pareceres médicos. O mesmo procedimento pode ser constatado nas reportagens sobre impotência masculina e automedicação ${ }^{19}$. Estas revistas atuam, assim, como instâncias legitimadoras da ciência. O discurso científico é traduzido em informação que se toma exclusiva fonte provedora da necessidade de segurança dos indivíduos e como a maior autoridade nos assuntos relacionados ao corpo humano. Inexiste, como aspira U. Beck, uma politização do tema, ou seja, o recurso a fontes não-científicas diversificadas, originárias de outras áreas da experiência social.

Quando as revistas invadem o espaço da vida familiar para tratar, por exemplo, de segurança e qualidade de vida $^{20}$, as instâncias mobilizadas para fornecer referentes que gerem uma reflexividade pública sobre o assunto deslocam-se da esfera do conhecimento mais abstrato para estatísticas de órgãos de segurança e saúde, para dados de especialistas em acidentes domésticos e rodoviários, em roubos e crimes urbanos, em assaltos virtuais pela internet $^{21}$. Neste ambiente têm autoridade discursiva instâncias médicas, centros de pesquisa, especialistas em áreas diversas ligadas a segurança física, domiciliar, saúde, justiça, controle da violência e a seguridade privada. Os conhecimentos que orientam a formulação das receitas de segurança da revista são todos oriundos de centros e institutos especializados no estudo e controle estatístico dos fatores de insegurança pessoal e urbana. Novamente então é o conhecimento especializado cientificamente monitorado que ocupa praticamente todo o espaço dedicado à exploração do tema. Fórmula e receitas sobre procedimentos, mudanças de comportamento, adoção de novas práticas preventivas têm como fonte de referência o conhecimento sistemático e especializado.

Afora este recurso hegemônico à ciência, o outro agente monitorador da experiência é a tecnologia. Ele aparece como produto da engenhosidade científica criado para lidar com os riscos e ameaças contemporâneos. A revista investe páginas em descrições de equipamentos que considera importantes seja, por exemplo, para os cuidados contra acidentes caseiros envolvendo crianças pequenas, seja para proteger jovens contra acidentes com skates, bicicletas, patinetes. Oferece também explicações detalhadas sobre as novas tecnologias presentes em veículos de passeio que, segundo a revista, "graças à evolução da tecnologia os automóveis de hoje são máquinas muito mais seguras" "22. Segue ainda outra descrição detalhada dos equipamentos de segurança de casas. Existe um arsenal tecnológico sofisticado à disposição do consumidor dos centros urbanos. A revista traz não apenas a diversidade dos equipamentos disponíveis no mercado, mas detalha, em fotos e textos explicativos sobre o funcionamento, eficácia e valor de uma grande variedade deles.

Entre as páginas com as reportagens tem-se encartes publicitários de firmas e equipamentos de segurança, de carros, de bancos eletrônicos e de seguradoras. Uma publicidade oportunistamente encaixada em meio a um discurso jornalístico de caráter científico e tecnológico que legitima a si mesmo e aos textos publicitários, à medida que eles vêm como bens extensivos ao receituário apresentado pela revista. Mas este é um procedimento padrão recorrente em publicações das mais diferentes áreas, seja no campo da estética feminina, do automobilismo, dos esportes, da música, do lazer, do corpo, da pecuária e da agricultura, ou do comércio.

Este é o exemplo de outro encarte sobre "Tecnologia e Consumo"23. Neste caso, explica o editorial, a revista está preocupada em tirar dúvidas dos consumidores sobre marcas e preços. Os repórteres testaram equipamentos, 
consultaram especialistas em diversas áreas, da saúde até a de informática em busca de um conteúdo jornalístico que servisse como "uma ferramenta poderosa para ajudar os leitores na hora de comprar" 24 . Novamente repete-se o padrão do recurso à fala autorizada de especialistas, mas, neste caso, sobretudo, da ostensiva exposição de bens tecnológicos, criando uma linha muito tênue, por vezes indiferençável, entre jornalismo e publicidade.

Nas reportagens ligadas a temáticas da vida urbana, um padrão semelhante se repete. Para tratar do tema da solidão humana ${ }^{25}$, o texto jornalístico recorre a um conjunto de especialistas, psicólogos, psiquiatras, sociólogos, antropólogos, além de estatísticas do IBGE e depoimento de indivíduos com formação universitária, profissão e posição social estáveis. Aqui ocorre um misto de referentes dados por especialistas com narrativas de experiências privadas. Um modelo semelhante de abordagem também é encontrado na matéria sobre os desafios da vida profissional autônoma ${ }^{26}$. Um conjunto de dados estatísticos é associado ao depoimento de casos específicos. O mesmo ocorre em outra reportagem sobre comportamento de jovens de classe média ${ }^{27}$. Tem-se o discurso de neurologistas, psicólogos, sociólogos, agências de pesquisa de opinião e instituto de pesquisa em meio a depoimentos de jovens sobre suas preferências, comportamentos e perspectivas para o futuro. Nestes tipos de reportagem desenvolve-se uma reflexividade a partir de uma mistura entre a fala de especialistas e descrições diretas de experiências de indivíduos anônimos cujo perfil se encaixa na temática em questão. Realiza-se não uma politização do tema, mas uma espécie de terapia coletiva baseada em depoimentos.

\section{Conclusão}

Assim, de modo geral, observase uma rotina discursiva cujos mecanismos se sustentam sobre o conhecimento especializado. As revistas em análise atuam como ponte entre a ciência e o mundo leigo. Levam a ciência até a realidade concreta dos riscos da vida social contemporânea. Promovem, então, uma reflexividade baseada na atualização dos indivíduos para a solução de problemas permanentemente em aberto. $\mathrm{O}$ conhecimento científico, pela sua própria natureza, substitui o exercício da pluralidade de pontos de vista por modelos de conduta cientificamente calculados e avaliados. Neste sentido, a perspectiva de Anthony Giddens se confirma. As incertezas da experiência cotidiana são monitoradas e controladas por sistemas especializados como mecanismos a serviço da redução da ansiedade e dos sentimentos de insegurança. Dentro do estilo de vida dos leitores das revistas analisadas, o conhecimento científico funciona como um mecanismo de confiança que orienta comportamentos, valores e escolhas.

Escolhas que, em parte expressiva do material analisado, envolve uma profunda simbiose com o mercado. Ciência e mercado, com seus bens e serviços, associam-se no processo de provimento de sentimentos de segurança, conforto e defesa contra as ameaças da vida urbana. Os bens do mercado são uma versão prática de conhecimentos científicos aplicados a produtos, legitimados por estes em termos de eficácia e necessidade. A mídia assume a defesa da necessidade então da recorrência ao mercado como fonte vital de segurança ontológica.
(24) Idem, p. 07.

(25) Reportagem de capa "O Fantasma da Solidão", em Veja, ed. 1710, ano 34, n²9, de 25.07.2001 (26) "A Vida sem Patrão", Veja, ed. 1705, ano 34, n²4, de 20.06.2001

(27) Reportagem de capa "Tá Ligado", no interior da revista é apresentada como "Geração Zapping", pp. 82-87, IstoÉ, n' 1659 , de 18.07.2001 


\section{Bibliografia do Artigo}

BECK, Ulrich. The Reinvention of Politics - Rethinking Modernity in the Global Social Order. Cambridge, Polity Press, 1997.

BECK, Ulrich, GIDDENS, Anthony e LASH, Scott. Modernização Reflexiva - Política, Tradição e Estética na Ordem Social Moderna. SP, Ed. Unesp, 1997.

FEATHerstone, Mike. Cultura de Consumo e Pós-Modernismo. SP, Studio Nobel, 1995.

GIDDENS, Anthony. Mundo em Descontrole - O Que a Globalização

Está Fazendo de Nós. RJ, Record, 2000.

HABERMAS, Jürgen. Mudança Estrutural da Esfera Pública. RJ, Tempo Brasileiro, 1984. . A Constelação Pós-Nacional - Ensaios Políticos. SP, Littera Mundi, 2001.

Isto É, $\mathrm{n}^{\circ} 1656$, de 27.06.2001.

Isto É, $\mathrm{n}^{\circ} 1659$, de 18.07.2001.

Isto É, $\mathrm{n}^{\circ} 1671$, de 10.10.2001.

Veja Especial, ano 34, n 23, de 13.06.2001.

Veja, ed. 1705, ano 34, $\mathrm{n}^{\circ}$ 24, de 20.06.2001.

Veja, ed. 1706, ano 34, n 25, de 27.06.2001. 